\title{
Statistical analysis of thermal conductivity of nanofluid containing decorated multi-walled carbon nanotubes with $\mathrm{TiO}_{2}$ nanoparticles
}

\author{
SEDIGHEH ABBASI, SEYED MOJTABA ZEBARJAD* ${ }^{\dagger}{ }^{\dagger}$, SEYED HOSSEIN NOIE BAGHBAN \\ and ABBAS YOUSSEFI ${ }^{\dagger \dagger}$ \\ Department of Chemical Engineering, Faculty of Engineering, Ferdowsi University of Mashhad, Azadi Square, \\ Mashhad, Iran \\ ${ }^{\dagger}$ Department of Material Science and Engineering, Faculty of Engineering, Ferdowsi University of Mashhad, \\ Azadi Square, Mashhad, Iran \\ ${ }^{\dagger}$ Par-e-Tavous Research Institute, Mashhad, Iran
}

MS received 16 June 2013; revised 1 September 2013

\begin{abstract}
In this paper, we report for the first time the statistical analysis of thermal conductivity of nanofluids containing $\mathrm{TiO}_{2}$ nanoparticles, pristine MWCNTs and decorated MWCNTs with different amounts of $\mathrm{TiO}_{2}$ nanoparticles. The functionalized MWCNT and synthesized hybrid of $\mathrm{MWCNT}-\mathrm{TiO}{ }_{2}$ were characterized using transmission electron microscopy (TEM). TEM image confirmed that the ends of MWCNTs were opened during their oxidation of them in $\mathrm{HNO}_{3}$ and $\mathrm{TiO}_{2}$ nanoparticles successfully attach to the outer surface of oxidized MWCNTs. Thermal conductivity measurements of nanofluids were analysed via two-factor completely randomized design and comparison of data means is carried out with Duncan's multiple-range test. Statistical analysis of experimental data show that temperature and weight fraction have a reasonable impact on the thermal conductivity of all tested nanofluids $(\alpha=0.05)$. The results also show that increased temperature and weight fraction leads to the increased thermal conductivity.
\end{abstract}

Keywords. MWCNT; $\mathrm{TiO}_{2}$ nanoparticles; thermal conductivity; nanofluid.

\section{Introduction}

Dispersing the particles with a typical size of $<100 \mathrm{~nm}$ in the conventional heat transfer fluids such as oil and water leads to the production of new classes of heat transfer fluids, which are called nanofluids (Arani and Amani 2012). The application of particles with nanometer size reduced the clogging of flow channels, eroding of pipelines and pressure drop. In addition, compared with millimetre- or micrometer-sized particle suspensions, nanofluid have better long-term stability and greater thermal conductivity. Up to date, various types of nanoparticles such as metallic, non-metallic, polymeric and nanotubes were suspended in base fluids (Duangthongsuk and Wongwises 2009). Among the various kinds of nanoparticles, carbon nanotubes (CNTs), owing to their unique structure, high aspect ratio and excellent thermal conductivity, have attracted much attention. As a result, dispersing CNTs in a base fluid can enhance the thermal conductivity of nanofluid (Phuoc et al 2011). Dispersibility of nanoparticles in the base fluid is a key factor in the stability of nanofluids. Therefore, the application of dispersing agent such as surfactant can enhance the stability of nanofluids (Assael et al 2005). The previous study

*Author for correspondence (zebarjad@um.ac.ir) reported that the surfactant molecules which introduce to the outer surface of nanoparticles and CNTs increased the thermal resistance. Thus the application of surfactant decreased the thermal conductivity of nanofluids (Huxtable et al 2003). Introducing the oxygencontaining groups such as hydroxyl and carboxyl groups to the outer surface of carbon nanotubes has a significant effect on the high stability of CNTs nanofluids, which leads to the enhancement of thermal conductivity (Kyotani et al 2001).

Murshed et al (2005) reported the thermal conductivity of $\mathrm{TiO}_{2}$ /water-based nanofluids as a function of the shape of nanoparticles. They investigated $\mathrm{TiO}_{2}$ nanoparticles of rod shapes of $10 \mathrm{~nm} \times 40 \mathrm{~nm}$ (diameter by length) and in sphere shapes of $15 \mathrm{~nm}$. Their experimental results show that the thermal conductivity of nanofluids was much higher than that of base fluid even in a small amount of nanoparticles. Meanwhile, they observed that volume fraction, particle size and shape of nanoparticles also influence the thermal conductivity enhancement of nanofluids.

Zhang et al (2007) investigated the heat transfer performance of $\mathrm{TiO}_{2}$ /water nanofluid for various volume fractions and temperatures. They observed that the effective thermal conductivities of nanofluids have not shown any anomalous enhancements. 
Chen et al (2008) reported the thermal conductivity of nanofluids containing multi-walled carbon nanotubes (MWCNTs), which were treated using mechanochemical reaction method to enhance their dispersibility. Their results showed the thermal conductivity enhancement up to $17 \cdot 5 \%$ at volume fraction of $0 \cdot 01$.

Raykar and Singh (2010) investigated the thermal conductivity of nanofluids containing carbon nanotubes as a function of temperature and Brownian motion. They observed that Brownian motion played a key role in the thermal conductivity of nanofluids.

Talaei et al (2011) studied the thermal conductivity of nanofluids containing MWCNTs with various concentrations of functional group. They reported that the concentration of functional groups which attached to the surface of MWCNTs in different methods is varied. Meanwhile they observed that thermal conductivity of nanofluids increased with respect to the functionalized group concentration.

Xie and Chen (2009) investigated the thermal conductivity of nanofluids of MWCNs into ethylene glycol base fluid. Their experiments showed that the thermal conductivity was enhanced with nanotube loading and temperature.

Meibodi et al (2010) have reported the thermal conductivity and stability of CNT/water nanofluids as a function of nanoparticle size and concentration, surfactant type and concentration, $\mathrm{pH}$, temperature, power of ultrasonication and elapsed time after ultrasonication and their interactions. Their results revealed that, as a result of the statistical analysis of the thermal conductivity, elapsed time after ultrasonication had the most significant effect and $\mathrm{pH}$ was not more significant.

Jha and Ramaprabhu (2009) investigated the thermal conductivity of nanofluids containing MWCNTs which were decorated with $\mathrm{Pd}, \mathrm{Au}$ and Ag crystalline metal nanoparticle. They used water and ethylene glycol as base fluids without any surfactant. Their experiments corroborated that the thermal conductivity of these nanofluids increases with increase in concentration of metal-MWNT and with temperature.

Nevertheless the effect of many factors such as temperature, $\mathrm{pH}$, concentration, size, shape and type of nanoparticles on the thermal conductivity of nanofluids have been reported by many researchers in the previous studies. In addition, a few papers have been published on the thermal conductivity of nanofluids containing decorated CNTs with nanoparticles. Although the thermal conductivity enhancement in the nanofluid containing decorated MWCNT with Pd, Au and Ag crystalline metal nanoparticle was investigated by previous investigators, it is clear that these nanoparticles have high intrinsic thermal conductivity. Therefore, the hybrid of these nanoparticles and MWCNTs can enhance the thermal conductivity of nanofluids. In this paper, we decided to choose $\mathrm{TiO}_{2}$ nanoparticles with low intrinsic thermal conductivity, such that we could investigate whether the thermal conductivity enhancement of nanofluids containing the hybrid of $\mathrm{TiO}_{2}$ nanoparticles and MWCNTs are considerable or not.

Till now, no paper has reported the effect of decorated MWCNTs with metal oxide such as $\mathrm{TiO}_{2}$ nanoparticles with different amounts of nanoparticles loading. Meanwhile, the statistical analysis of the thermal conductivity of these nanofluids has never been investigated before. Therefore, in this paper, we want to investigate, for the first time, the statistical analysis of the thermal conductivity of nanofluid containing modified MWCNTs with various amounts of $\mathrm{TiO}_{2}$ nanoparticles.

\section{Materials and experimental}

$\mathrm{TiO}_{2}$ nanoparticles were prepared by the hydrolysis of titanium tetrachloride $\left(\mathrm{TiCl}_{4}, \mathrm{M}=189 \cdot 79,99 \%\right.$, Merck). The synthesis procedure of $\mathrm{TiO}_{2}$ nanoparticles is as follows. A certain amount of $\mathrm{TiCl}_{4}$ was dissolved in distilled water at ambient temperature and stirred for about $5 \mathrm{~h}$. Then the temperature of the solution was increased to $80{ }^{\circ} \mathrm{C}$ and stirred for $24 \mathrm{~h}$. Finally, the solution was filtrated using the Whatman filter paper (Ashless, circies, $125 \mathrm{~mm}$ ) and the separated $\mathrm{TiO}_{2}$ nanoparticles dried at room temperature and calcined at $370{ }^{\circ} \mathrm{C}$ for $3 \mathrm{~h}$.

For the synthesis of decorated MWCNTs with $\mathrm{TiO}_{2}$ nanoparticles, the following materials are needed. MWCNTs (average diameter of $40-60 \mathrm{~nm}$ and lengths ranging from 5 to $15 \mu \mathrm{m})$, nitric acid $\left(\mathrm{HNO}_{3}, \mathrm{M}=63\right.$, 65\%, Merck), hydrochloride acid ( $\mathrm{HCl} 37 \mathrm{wt} \%$, Merck) and titanium tetrachloride which is mentioned earlier. The details of the synthesis procedure of MWCNT- $\mathrm{TiO}_{2}$ has been described in our previous work (Abbasi et al 2013). Only a brief description is given here. The synthesis includes two steps. First, oxidation of MWCNTs with nitric acid for about $2 \mathrm{~h}$ in an ultrasound bath and $2 \mathrm{~h}$ in a stirrer at high speed to open the end of MWCNTs and introduce the oxygen-containing groups to their outer surface. Then, the oxidized MWCNTs were washed with distilled water until the $\mathrm{pH}$ value of the drained water reached neutral and dried overnight. Secondly, a certain amount of $\mathrm{TiCl}_{4}$ was dissolved in $100 \mathrm{~mL}$ distilled water, followed by adding a little $\mathrm{HCl}(37 \mathrm{wt} \%)$ to the distilled water before $\mathrm{TiCl}_{4}$ was dissolved in the water. Then, $\sim 75 \mathrm{mg}$ of the functionalized MWCNTs were added to the solution and dispersed using ultrasound bath for $2 \mathrm{~h}$ and stirred for $22 \mathrm{~h}$. Finally, the temperature of solution increased to $80^{\circ} \mathrm{C}$ and stirred for $3 \mathrm{~h}$. then filtered, dried at $80^{\circ} \mathrm{C}$ for $1 \mathrm{~h}$ and calcined at $370^{\circ} \mathrm{C}$ for $3 \mathrm{~h}$.

Thermal conductivity of nanofluids was measured using KD2 Prothermal property analyser purchased from Decagon Devices Inc. The measurements were carried out using the single needle (KS-1) of $60 \mathrm{~mm}$ length and $1.3 \mathrm{~mm}$ diameter and accuracy $\pm 0.01 \mathrm{Wm}^{-1} \mathrm{~K}^{-1}$ from 
0.02 to $0.2 \mathrm{Wm}^{-1} \mathrm{~K}^{-1}$. The effect of temperature and concentration was studied in the range of $25-70{ }^{\circ} \mathrm{C}$ and $0 \cdot 25$ $1.5 \mathrm{wt} \%$, respectively. For controlling the temperature during the measurements, a water bath (Thermo Haake K10 TT4310) at constant temperature which circulated the water around the double-walled cylindrical container of samples was connected to the KD2 Pro device. For accurate results, the measurements were repeated several times and only three measurements which had the mean correlation coefficient $r^{2}>0.9998$ were considered. Transmission electron microscopy (TEM) micrographs of acid-treated and modified MWCNTs with $\mathrm{TiO}_{2}$ nanoparticles were obtained using a LEO 912AB system which operated at $120 \mathrm{kV}$.

Statistical analysis of the thermal conductivity of nanofluids in different nanofluids was performed with a twofactor completely randomized design using Mstac (Ver. 1.42) and significant differences between means were determined by Duncan's multiple range test. $P$ values $<0.05$ were considered statistically significant. For the investigation, the combined effects of temperature and weight fraction on the thermal conductivity of nanofluids, response surface method was measured out using Minitab Release software (Ver. 11.12).

\section{Results and discussion}

\subsection{Oxidation of MWCNTs}

As a result of oxidation of MWCNTs in nitric acid, the ends of tubes which closed with catalyst particles were opened. Furthermore, the acid treatment of MWCNTs leads to the cutting of MWCNTs to a shorter length. During oxidation of MWCNTs, the $s p^{2}$ hybridization of MWCNTs can be changed to $s p^{3}$. Therefore, the outer surface and open ends of MWCNTs functionalized with oxygen-containing groups such as acid carboxylic $(-\mathrm{COOH})$ and hydroxyl $(-\mathrm{OH})$. Figure 1 shows TEM image of acid treatment of MWCNTs in nitric acid.

\subsection{Decoration of MWCNTs}

Hydrolysis of $\mathrm{TiCl}_{4}$ in the solution of functionalized MWCNTs leads to the production of titanium ions. These ions can be absorbed by hydroxyl and acid carboxylic groups which introduce to the outer surface of MWCNTs during the acid treatment process. These functional groups act as active sites and titanium ions attach due to electrostatic attraction. Therefore, the nucleation of $\mathrm{TiO}_{2}$ nanoparticles carried out and the calcination of the powder leads to the formation of nanocrystalline $\mathrm{TiO}_{2}$ on the outer surface of MWCNTs. It should be mentioned that the amount of $\mathrm{TiCl}_{4}$ has a key role in the nucleation and formation of $\mathrm{TiO}_{2}$ nanoparticles. Therefore, in this study we synthesized MWCNTs- $\mathrm{TiO}_{2}$ with 34 and 61\% of $\mathrm{TiO}_{2}$ nanoparticles by changing the amount of $\mathrm{TiCl}_{4}$. Figure 2 illustrates TEM image of decorated MWCNTs.

\subsection{Data analysis and statistical studies}

3.3a Effect of temperature on thermal conductivity of nanofluids: Figure 3 depicts the effect of temperature

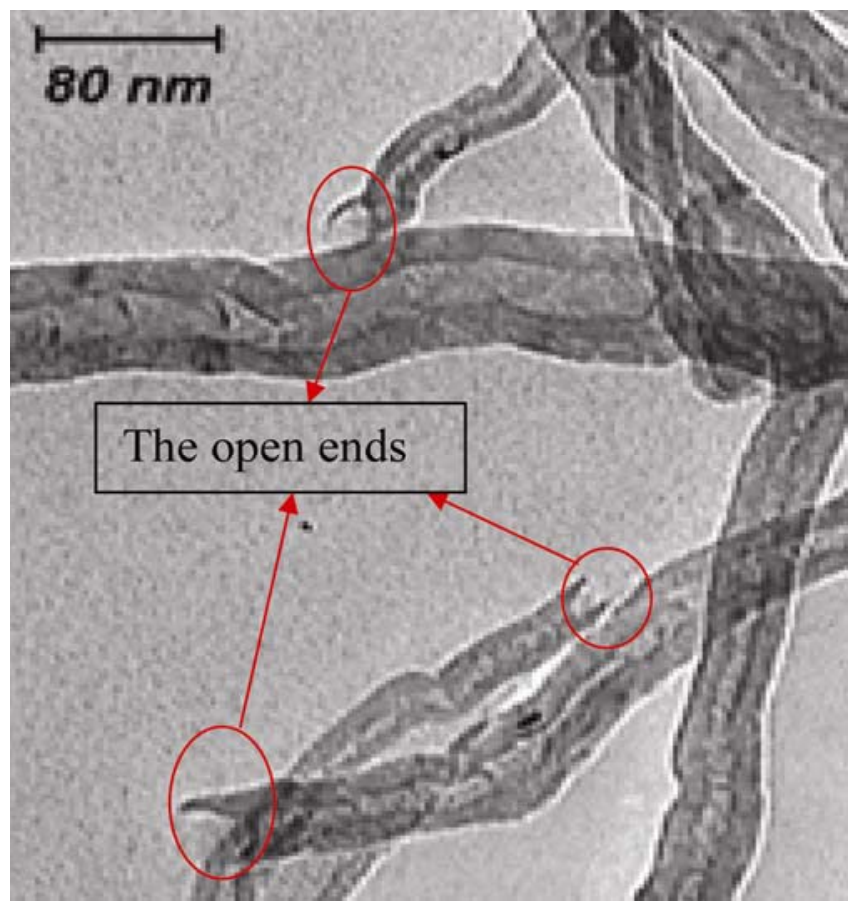

Figure 1. TEM image of acid-treated MWCNTs.

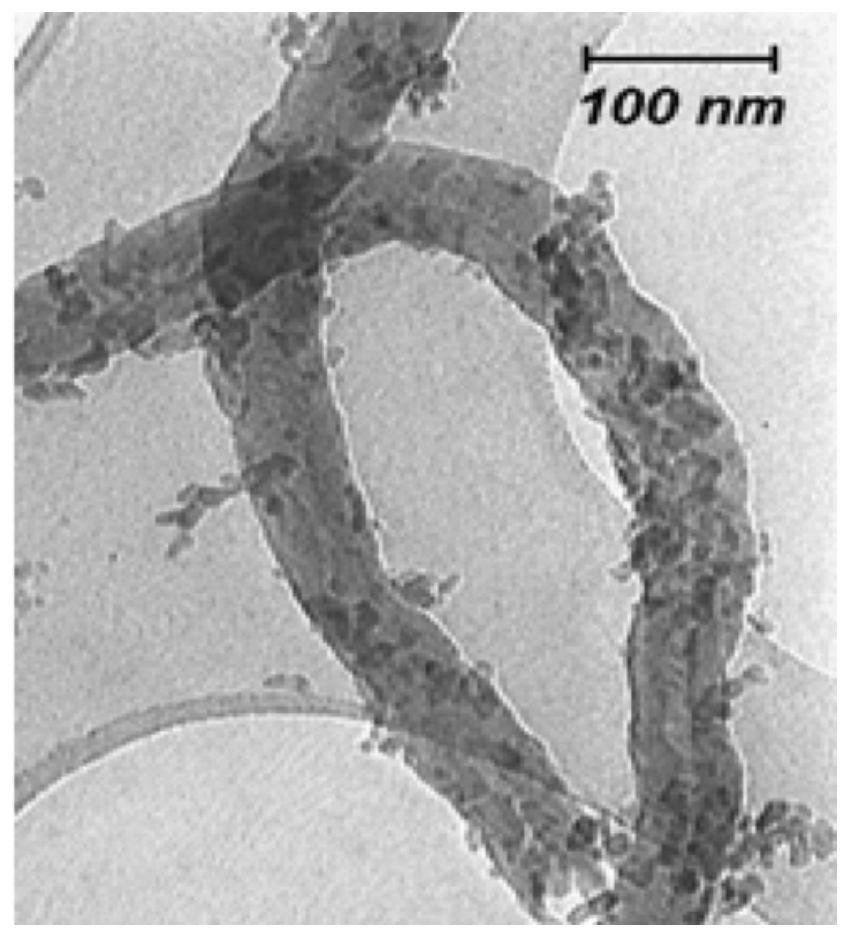

Figure 2. TEM image of MWCNTs- $-\mathrm{TiO}_{2}$. 
on the thermal conductivity of $\mathrm{TiO}_{2}$ nanofluids. As can be deduced, there was a completely significant difference among different temperatures from the aspect of thermal conductivity. By increasing the temperature from 25 to $70{ }^{\circ} \mathrm{C}$, the thermal conductivity of $\mathrm{TiO}_{2}$ nanofluid was increased. Index was increased from $25^{\circ} \mathrm{C}$ $\left(0.5907 \mathrm{Wm}^{-1} \mathrm{~K}^{-1}\right)$ to $40{ }^{\circ} \mathrm{C}\left(0.6426 \mathrm{Wm}^{-1} \mathrm{~K}^{-1}\right)$ equal to 8.78\%; from 40 to $55^{\circ} \mathrm{C}\left(0.6623 \mathrm{Wm}^{-1} \mathrm{~K}^{-1}\right)$ equal to $3.06 \%$ and from 55 to $70{ }^{\circ} \mathrm{C}\left(0.686 \mathrm{Wm}^{-1} \mathrm{~K}^{-1}\right)$ equal to $3.57 \%$. In addition, the thermal conductivity of $\mathrm{TiO}_{2}$ nanofluid during the increase of the temperature, from 25 to $70{ }^{\circ} \mathrm{C}$, was increased to $\sim 16 \%$.

The influence of temperature on the thermal conductivity of pristine MWCNTs nanofluid is shown in figure 4. It is clear that there was a significant difference among four temperatures for thermal conductivity of pristine MWCNTs nanofluid $(\alpha=0 \cdot 05)$. Moreover, it can be observed that by increasing the temperature, thermal conductivity also increased. Minimum thermal conductivity was related to a temperature of $25^{\circ} \mathrm{C}$ equal to 0.6181 $\mathrm{Wm}^{-1} \mathrm{~K}^{-1}$. The value of this quality at $40{ }^{\circ} \mathrm{C}$ was increased to $0.6852 \mathrm{Wm}^{-1} \mathrm{~K}^{-1}$, e.g. $10 \cdot 85 \%$, at $55^{\circ} \mathrm{C}$ increased to $0.7202 \mathrm{Wm}^{-1} \mathrm{~K}^{-1}$, e.g. $5 \cdot 10 \%$ and at $70{ }^{\circ} \mathrm{C}$ increased to $0.7572 \mathrm{Wm}^{-1} \mathrm{~K}^{-1}$, e.g. $5 \cdot 13 \%$. Therefore, the augmentation of the thermal conductivity of pristine MWCNTs nanofluid from 25 to $70{ }^{\circ} \mathrm{C}$ is equal to $22 \cdot 50 \%$. Meanwhile, comparing the augmentation of the thermal conductivity of pristine MWCNTs nanofluid and $\mathrm{TiO}_{2}$ nanofluid revealed that increasing thermal conductivity of nanofluid containing pristine MWCNTs nanofluid $(22 \cdot 5 \%)$ is $>\mathrm{TiO}_{2}$ nanofluid (16\%). This can be due to the excellent intrinsic thermal conductivity of MWCNTs. In other words, the augmentation of the thermal conductivity of pristine MWCNTs nanofluid is $40 \cdot 62 \%$ greater than that of $\mathrm{TiO}_{2}$ nanofluid. Because in the nanofluids containing sphere metal or metal oxide nanoparticles, the Brownian motion of nanoparticles affected the variation of thermal conductivity with temperature (Das et al 2003). Nevertheless, in the nanofluids containing MWCNTs, in addition to the Brownian motion of MWCNTs, the chemical functionalized groups have a key effect on the amount of energy which transfers into the nanofluids by changing the temperature (Chen and Xie 2010).

It is clear that an increase in the temperature leads to the weakness of the hydrogen bond of water molecules. As a result, the number of free water molecules in the nanofluid increases. Therefore, the produced free water molecules arrange around MWCNTs' surface as a liquid layer due to the chemical surfaces of MWCNTs and van der Waals force between the water molecules. The thermal conductivity of the produced layer is higher than that of bulk liquid. Therefore, it can be deduced that the chemical functionalized groups of MWCNTs have a significant effect on the enhancement of thermal conductivity of nanofluid.
Figures 5 and 6 illustrate the effect of temperature on the thermal conductivity of nanofluids containing MWCNTs- $\mathrm{TiO}_{2}$ with 61 and $34 \%$ of $\mathrm{TiO}_{2}$ nanoparticles, respectively. It is clear that in both the nanofluids, there was a significant difference among four temperatures for thermal conductivity of $\mathrm{MWCNTs}-\mathrm{TiO}_{2}$ nanofluid ( $\alpha=0.05$ ) and the thermal conductivity of both nanofluids increased with respect to the temperature. From figures 5 and 6 , it can be inferred that the least thermal conductivity was recorded for temperature of $25^{\circ} \mathrm{C}$ equal to $0.6342 \mathrm{Wm}^{-1} \mathrm{~K}^{-1}$ and $0.652 \mathrm{Wm}^{-1} \mathrm{~K}^{-1}$ for nanofluids containing MWCNTs- $\mathrm{TiO}_{2}$ with 61 and $34 \%$ of $\mathrm{TiO}_{2}$ nanoparticles, respectively. In addition, maximum thermal conductivity was related to the temperature of $70^{\circ} \mathrm{C}$

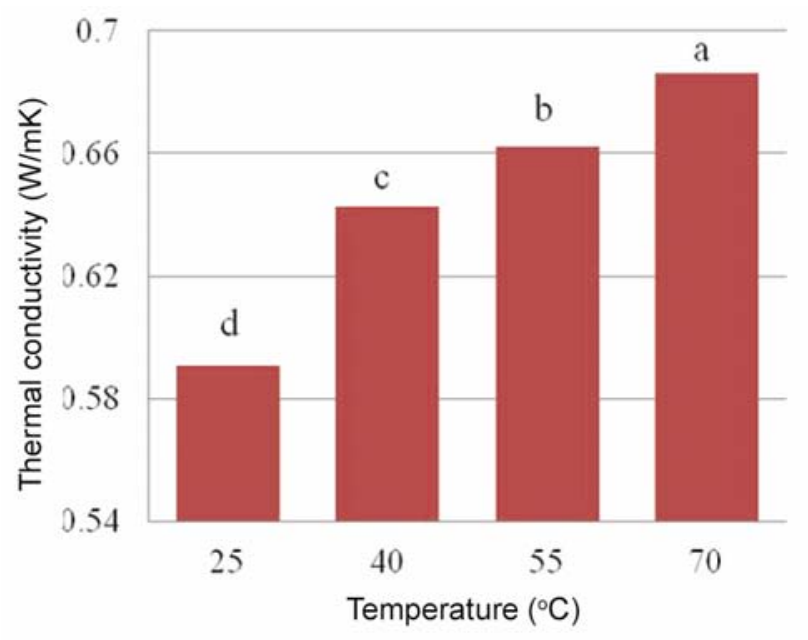

Figure 3. Effect of temperature on thermal conductivity of $\mathrm{TiO}_{2}$ nanofluid, means with different letters are significantly different based on Duncan's multiple range test $(\alpha=0 \cdot 05)$.

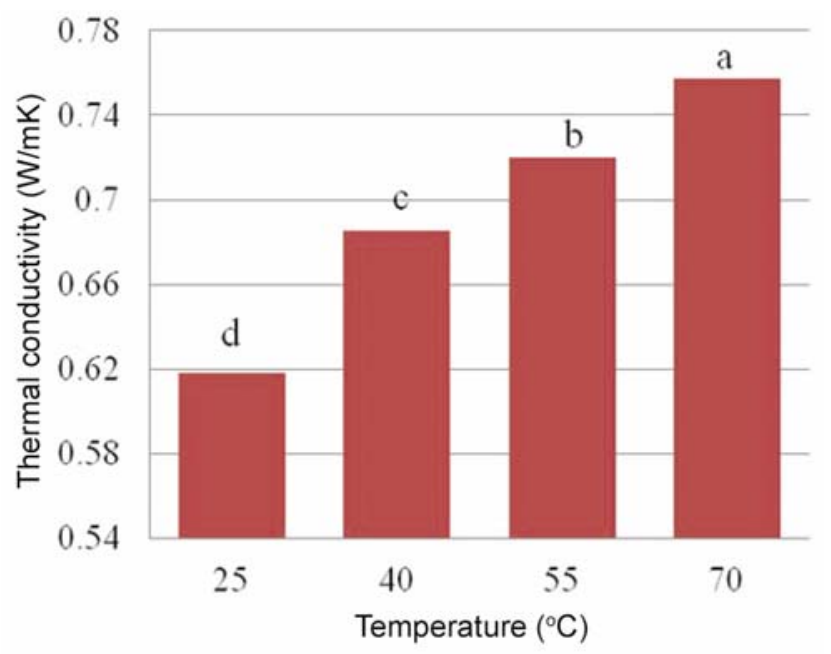

Figure 4. Effect of temperature on thermal conductivity of MWCNT nanofluid, means with different letters are significantly different based on Duncan's multiple range test $(\alpha=0.05)$. 
equal to $0.7737 \mathrm{Wm}^{-1} \mathrm{~K}^{-1}$ and $0.7896 \mathrm{Wm}^{-1} \mathrm{~K}^{-1}$ for nanofluids containing MWCNTs- $\mathrm{TiO}_{2}$ with 61 and 34\% of $\mathrm{TiO}_{2}$ nanoparticles, respectively.

Meanwhile, it can be deduced that in all the tested temperatures, by increasing the loading of $\mathrm{TiO}_{2}$ nanoparticles on the surface of MWCNTs, the thermal conductivity of MWCNT- $\mathrm{TiO}_{2}$ nanofluids also increased. It is due to the decreasing $\mathrm{TiO}_{2}$ nanoparticles content in the hybrid of MWCNTs- $\mathrm{TiO}_{2}$, the amount of MWCNTs which have higher intrinsic thermal conductivity increased.

3.3b Effect of concentration on thermal conductivity of nanofluids: The results of data variance showed that there was a significant difference among four weight fractions in statistical level of $5 \%$ on aspect of thermal conductivity of $\mathrm{TiO}_{2}$ nanofluids. Maximum thermal conductivity of $\mathrm{TiO}_{2}$ nanofluids was $0.6512 \mathrm{Wm}^{-1} \mathrm{~K}^{-1}$ at weight fraction of $1.5 \mathrm{wt} \%$ but its difference in comparison with thermal conductivity at weight fraction of $1 \mathrm{wt} \%$ $\left(0.6475 \mathrm{Wm}^{-1} \mathrm{~K}^{-1}\right)$ and $0.5 \mathrm{wt} \%\left(0.6437 \mathrm{Wm}^{-1} \mathrm{~K}^{-1}\right)$ was insignificant. Minimum thermal conductivity was related to the weight fraction of $0.25 \mathrm{wt} \%\left(0.6393 \mathrm{Wm}^{-1} \mathrm{~K}^{-1}\right)$ that it was $1 \cdot 18 \%$ less than that of weight fraction of $1.5 \mathrm{wt} \%$ (figure 7 ).

There was a significant difference among different weight fractions from the viewpoint of thermal conductivity of MWCNT nanofluids. It was observed that by increasing the weight fraction of MWCNT, thermal

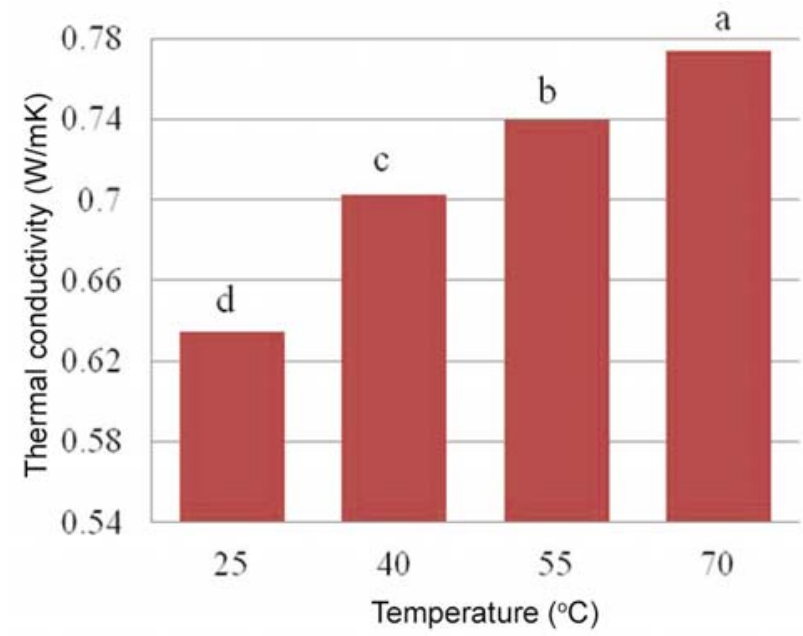

Figure 5. Effect of temperature on thermal conductivity of MWCNT- $-\mathrm{TiO}_{2}$ (61\%) nanofluid, means with different letters are significantly different based on Duncan's multiple range test $(\alpha=0 \cdot 05)$.

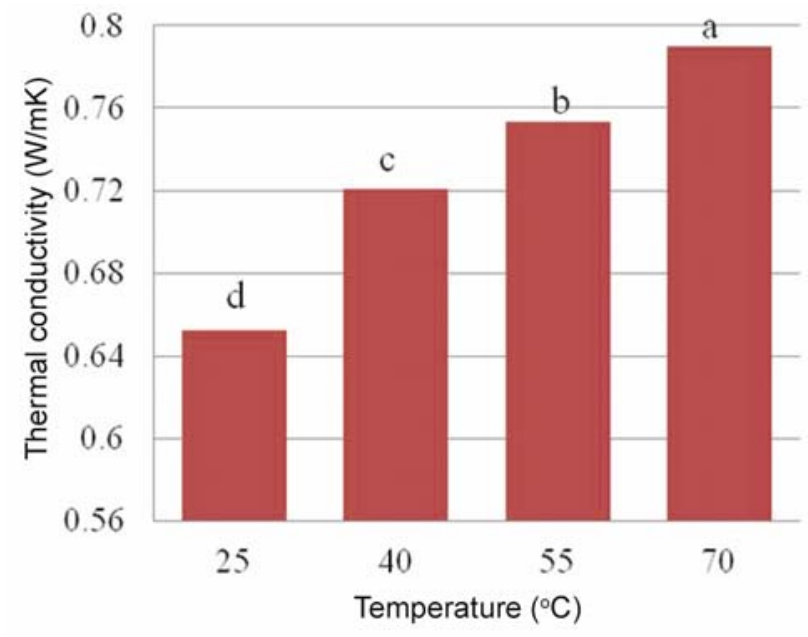

Figure 6. Effect of temperature on thermal conductivity of MWCNT- $-\mathrm{TiO}_{2}$ (34\%) nanofluid, means with different letters are significantly different based on Duncan's multiple range test $(\alpha=0 \cdot 05)$.

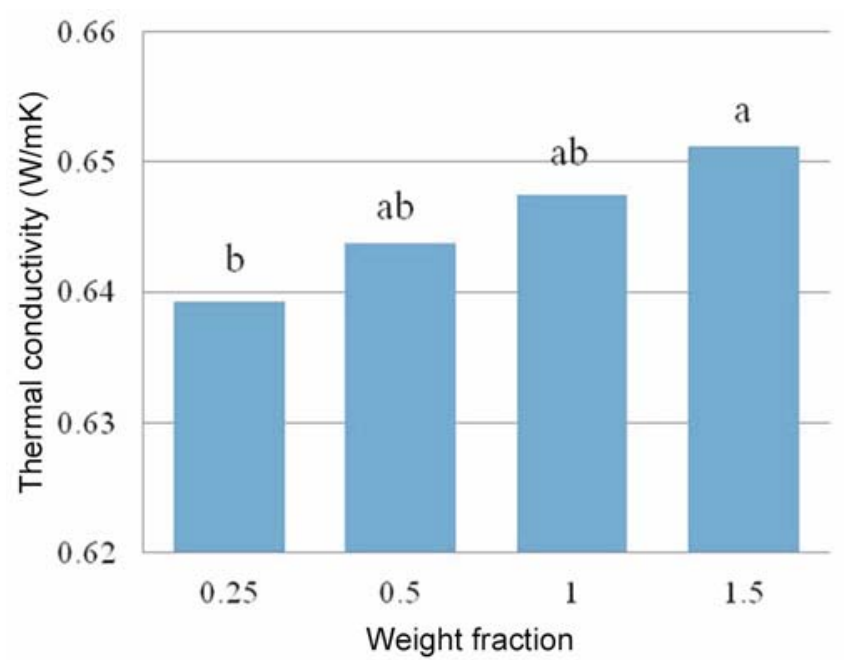

Figure 7. Effect of weight fraction on thermal conductivity of $\mathrm{TiO}_{2}$ nanofluid, means with different letters are significantly different based on Duncan's multiple range test $(\alpha=0 \cdot 05)$.

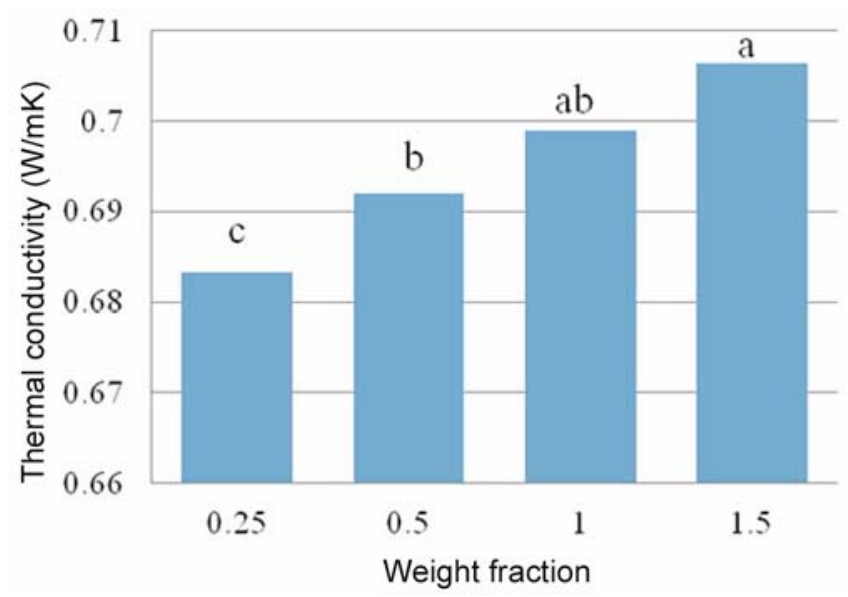

Figure 8. Effect of weight fraction on thermal conductivity of MWCNT nanofluid, means with different letters are significantly different based on Duncan's multiple range test $(\alpha=0 \cdot 05)$. 
conductivity also increased. Maximum thermal conductivity of MWCNT nanofluids was $0.7063 \mathrm{Wm}^{-1} \mathrm{~K}^{-1}$ at weight fraction of $1.5 \mathrm{wt} \%$ but its difference in comparison with thermal conductivity at weight fraction of $1 \mathrm{wt} \%$ $\left(0.699 \mathrm{Wm}^{-1} \mathrm{~K}^{-1}\right)$ was insignificant. Meanwhile, the thermal conductivity of MWCNT nanofluids during the increasing the weight fraction, from 0.5 to $1.5 \mathrm{wt} \%$ was increased equal to $3.36 \%$ (figure 8 ). Comparing the augmentation of the thermal conductivity of pristine MWCNTs nanofluid with temperature and concentration revealed that the increasing of thermal conductivity of nanofluid with temperature (22.5\%) is higher than that of with concentration (3.36\%), which is consistent with the results obtained by Ding et al (2006).

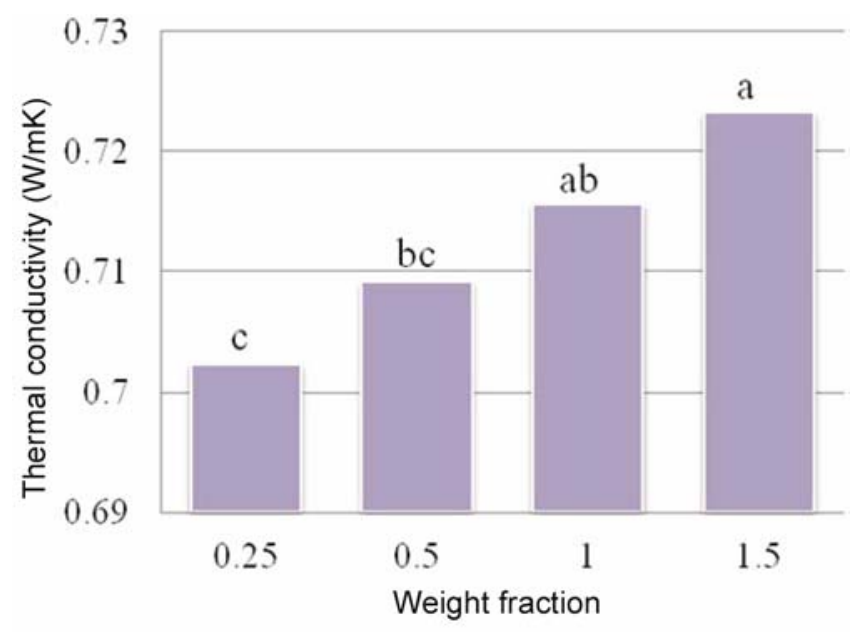

Figure 9. Effect of weight fraction on thermal conductivity of MWCNT- $\mathrm{TiO}_{2}$ (61\%) nanofluid, means with different letters are significantly different based on Duncan's multiple range test $(\alpha=0 \cdot 05)$.

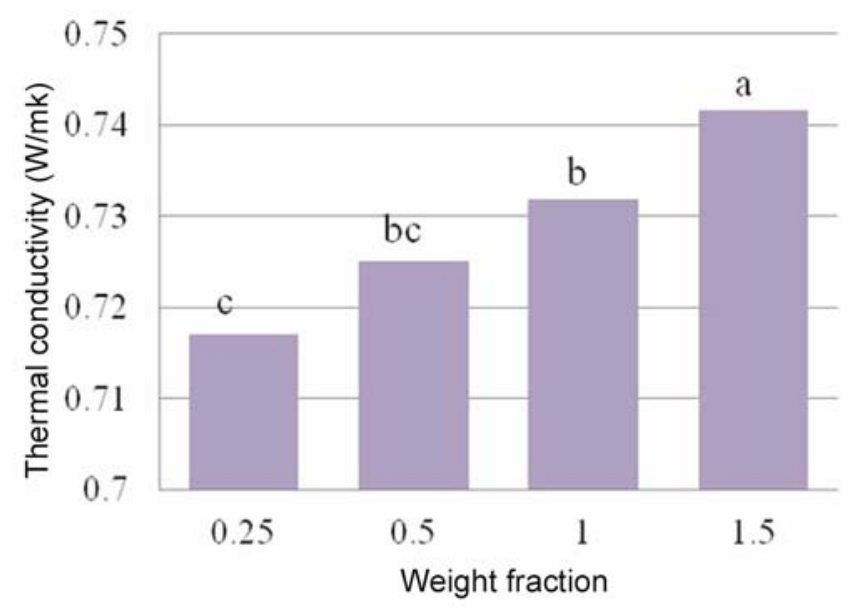

Figure 10. Effect of weight fraction on thermal conductivity of MWCNT- $-\mathrm{TiO}_{2}$ (34\%) nanofluid, means with different letters are significantly different based on Duncan's multiple range test $(\alpha=0 \cdot 05)$.
The influence of weight fraction on the thermal conductivity of nanofluids containing $\mathrm{MWCNT}-\mathrm{TiO}_{2}$ is shown in figures 9 and 10 for $\mathrm{MWCNT}-\mathrm{TiO}_{2}$ with 61 and $34 \% \mathrm{TiO}_{2}$ nanoparticles, respectively. It can be inferred that the minimum and maximum of thermal conductivity of both MWCNT- $\mathrm{TiO}_{2}$ nanofluids were related to weight fraction of 0.25 and $1.5 \mathrm{wt} \%$, respectively. According to the Duncan's multiple range test $(\alpha=0 \cdot 05)$, there was a significant difference among the highest and lowest weight fractions for thermal conductivity of both MWCNT- $-\mathrm{TiO}_{2}$ nanofluids, but difference between the weight fraction of 0.5 and $1 \mathrm{wt} \%$ was insignificant. In addition, increasing the weight fraction from 0.25 to $1.5 \mathrm{wt} \%$ led to the augmentation of thermal conductivity equals to 2.975 and $3.416 \%$ for $\mathrm{MWCNT}-\mathrm{TiO}_{2}$ nanofluids with 61 and $34 \% \mathrm{TiO}_{2}$ nanoparticles, respectively. Therefore, it can be deduced that increasing the thermal conductivity of $\mathrm{MWCNT}-\mathrm{TiO}_{2}$ nanofluids with $34 \%$ $\mathrm{TiO}_{2}$ nanoparticles is higher than that of MWCNT- $-\mathrm{TiO}_{2}$ nanofluids with $61 \% \mathrm{TiO}_{2}$ nanoparticles. It is due to the

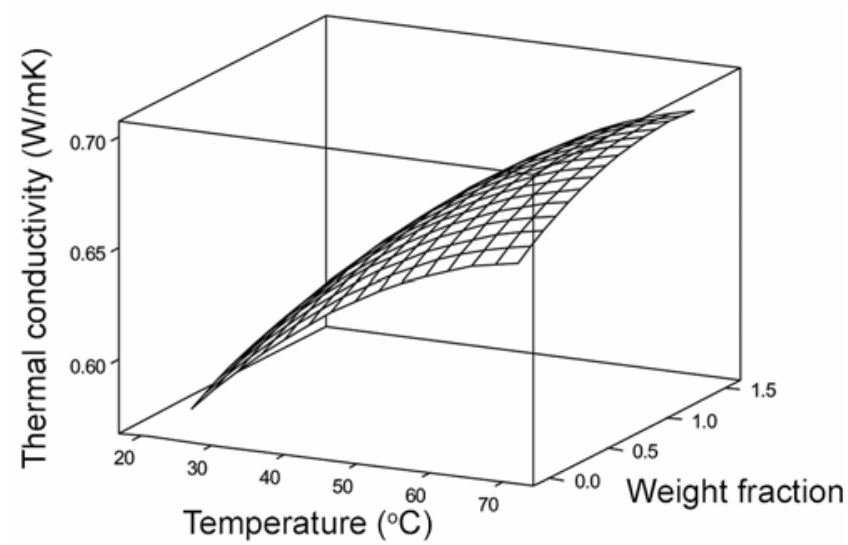

Figure 11. Response surface of thermal conductivity of $\mathrm{TiO}_{2}$ nanofluid vs temperature and weight fraction.

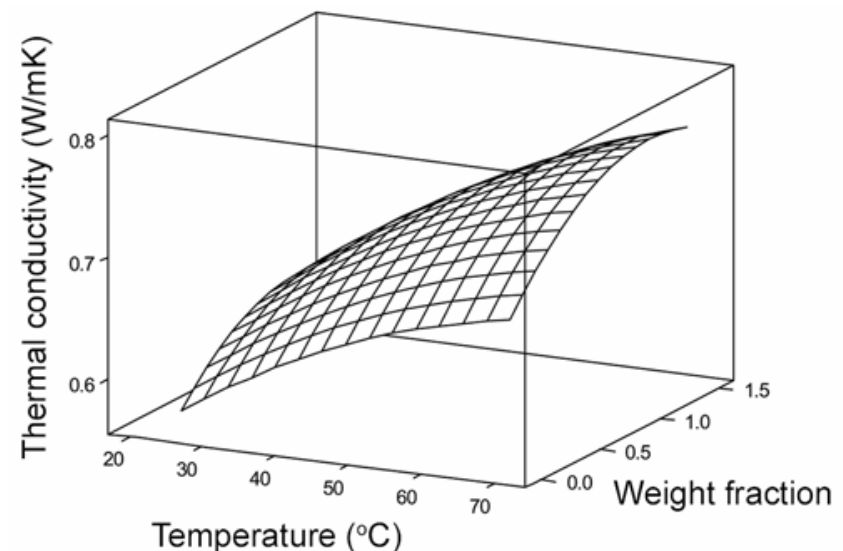

Figure 12. Response surface of thermal conductivity of MWCNT nanofluid vs temperature and weight fraction. 


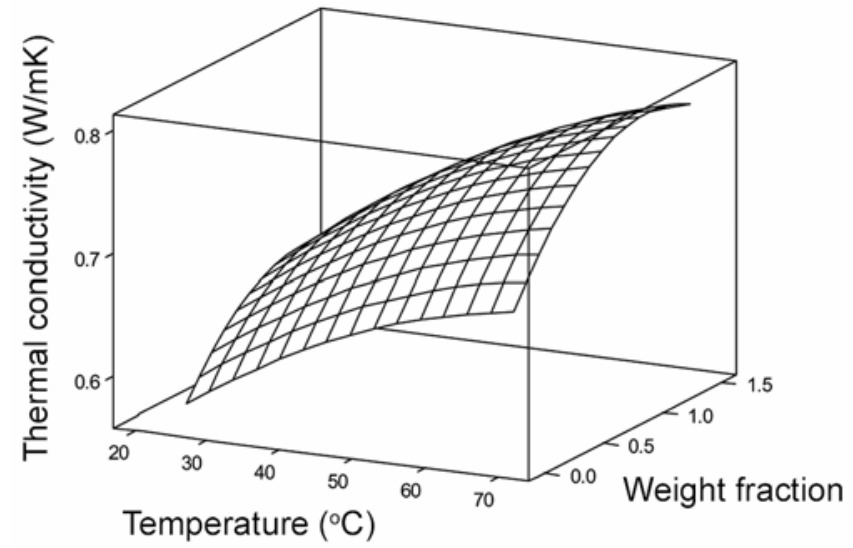

Figure 13. Response surface of thermal conductivity of MWCNT- $\mathrm{TiO}_{2}$ (61\%) nanofluid vs temperature and weight fraction.

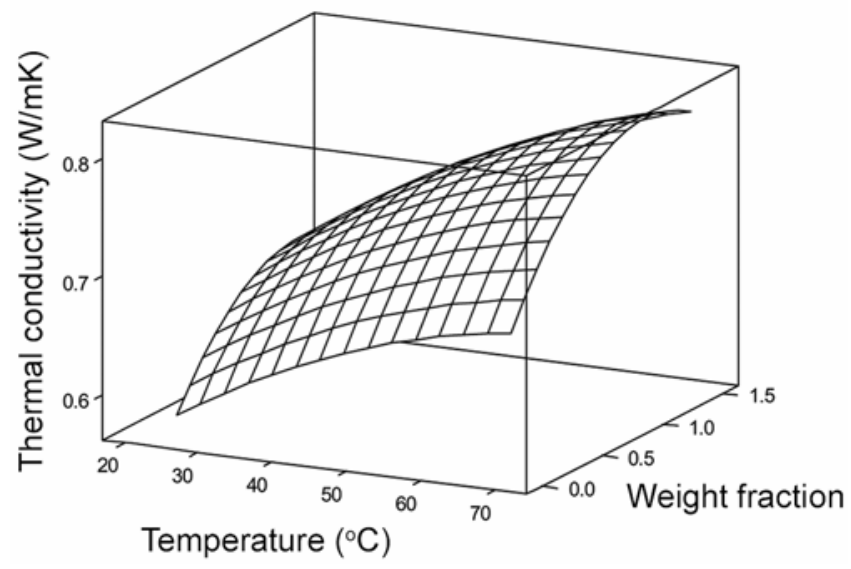

Figure 14. Response surface of thermal conductivity of MWCNT- $\mathrm{TiO}_{2}$ (34\%) nanofluid vs temperature and weight fraction.

increasing portion of MWCNT with higher intrinsic thermal conductivity in the hybrid of MWCNT- $\mathrm{TiO}_{2}$.

3.3c Response surface study: In this study, the response surface fitting method was used in order to study the combined effect of temperature and weight fraction on the thermal conductivity of nanofluid. Figure 11 shows the surface response of thermal conductivity of $\mathrm{TiO}_{2}$ nanofluid, which implies that the thermal conductivity of $\mathrm{TiO}_{2}$ nanofluid increases with increasing temperature and weight fraction, although the weight fraction variations of the thermal conductivity is less than that of temperature.

With respect to figure 12, which shows the surface response of thermal conductivity of MWCNT nanofluid with temperature and weight fraction, thermal conductivity increases with increasing temperature and weight fraction.

Figures 13 and 14 show the surface response of the thermal conductivity of MWCNT- $\mathrm{TiO}_{2}$ nanofluids with 61 and $34 \% \mathrm{TiO}_{2}$ nanoparticles, respectively. In both the cases, it is observed that thermal conductivity value increases with temperature and weight fraction. However, the influence of temperature is more considerable than that of weight fraction.

\section{Conclusions}

The present study investigated the thermal conductivity nanotubes containing $\mathrm{TiO}_{2}$ nanoparticle, pristine and decorated multi-walled carbon with $\mathrm{TiO}_{2}$ nanoparticles nanotubes. Statistical analysis of the experimental data shows that the temperature and weight fractions have a significant effect on the thermal conductivity of nanofluids. However, the influence of temperature on the thermal conductivity of nanofluids is more reasonable than that of weight fraction. Meanwhile, the results revealed that in all the tested temperatures, by increasing the loading of $\mathrm{TiO}_{2}$ nanoparticles on the surface of MWCNTs, the thermal conductivity of MWCNT- $\mathrm{TiO}_{2}$ nanofluids also increased.

\section{Acknowledgements}

The authors gratefully acknowledge the help by Mrs R Pesyan from Central Research Laboratory of Ferdowsi University of Mashhad and Mrs T Saeedi from Par-eTavous Research Institute.

\section{References}

Abbasi S, Zebarjad S M and Baghban S H N 2013 Engineerng 5 207

Arani A A A and Amani J 2012 Exp. Therm. Fluid Sci. 42107

Assael M J, Metaxa I N, Arvanitidis J, Christofilos D and Lioutas C 2005 Int. J. Thermophys. 26647

Chen L, Xie H, Li Y and Yu W 2008 Thermochim. Acta 47721

Chen L and Xie H 2010 Thermochim Acta 49767

Das S K, Putra N, Thiesen P and Roetzel W 2003 J. Heat Transfer. 125567

Ding Y, Alias H, Wen D and Williams R A 2006 Int. J. Heat Mass Trans. 49240

Duangthongsuk W and Wongwises S 2009 Int. J. Heat Mass Tran. 522059

Huxtable S T et al 2003 Nature Mater. 2731

Jha N and Ramaprabhu S 2009 J. Appl. Phys. 084317106

Kyotani T, Nakazaki S, Xu W and Tomita A 2001 Carbon 39 771

Meibodi M E, Sefti M V, Rashidi A M, Amrollahi A, Tabasi M and Kalal H S 2010 Int Commun. Heat Mass. 37319

Murshed S M S, Leong K C and Yang C 2005 Int. J. Therm. Sci. 44367

Phuoc T X, Massoudi M and Chen R H 2011 Int. J. Therm. Sci. 5012

Raykar V S and Singh A K 2010 Phys. Lett. A374 4618

Talaei Z, Mahjoub A R, Rashidi A M, Amrollahi A and Meibodi M E 2011 Int. Commun. Heat Mass. 38513

Xie H and Chen L 2009 Phys. Lett. A373 1861

Zhang X, Gu H and Fujii M 2007 Exp. Therm. Fluid Sci. 31593 